\title{
Taura syndrome virus in Penaeus vannamei shrimp originating from Hawaii
}

\author{
Jeong Wan Do ${ }^{1}$, Seung Ju Cha ${ }^{1,3}$, Nam Sil Lee ${ }^{1}$, Jae Youn Kang ${ }^{4}$, Yi Cheong Kim ${ }^{1}$, \\ Jin Woo Kim ${ }^{1}$, Jae Dong Kim ${ }^{2}$, Jeong Woo Park ${ }^{3, *}$ \\ ${ }^{1}$ Pathology Division, National Fisheries Research and Development Institute, Kijang, Busan 619-902, South Korea \\ ${ }^{2}$ Daesan Regional Maritime Affairs and Fisheries Office, Seosan 356-871, South Korea \\ ${ }^{3}$ Department of Biological Sciences, University of Ulsan, Ulsan 680-749, South Korea \\ ${ }^{4}$ National Fisheries Products Quality Inspection Service, Gyunggi-Do 410-315, South Korea
}

Previously in Diseases of Aquatic Organisms (DAO) we reported the detection of Taura syndrome virus (TSV) from Penaeus vannamei cultured in Cheonsu Bay, South Korea (we named it KOR-CsPv04TSV) and imported from Hawaii (KOR-ImPv05TSV) (Do et al. 2006). Lightner et al. (2007, this issue) commented that our report on the detection of TSV from Hawaiian $P$. vannamei is '...not only incorrect, but also disturbing...'. According to their Comment, their opinion was based on the following. First, TSV has not been detected in Hawaii since 1994 (Lightner et al. 1995) and the absence of TSV has been confirmed by a routine testing and surveillance program administered by the Hawaii Aquaculture Development Program. Second, the Oceanic Institute has developed specific pathogen-free (SPF) shrimp stocks and the Hawaiian shrimp culture industry has produced and exported only SPF shrimp (Wyban et al. 1993, Pruder et al. 1995). Third, there were no complaints from any importing country regarding broodstock exports from Hawaii in 2004, 2005 or 2006. In addition, Lightner et al. (2007) stated that, even though the Hawaiian supplying company requested that we (i.e. the National Fisheries Research and Development Institute of Korea, NFRDI) carry out additional testing with additional samples from the same stock, we did not respond. They further stated that, in failing to notify the Competent Authority (in this case, the Hawaiian Aquaculture Development Program), we did not follow World Animal Health Organization (OIE) guidelines. They concluded that we incorrectly interpreted our test results, which were more likely the result of mislabeling of samples or within-laboratory contamination.

In reply to their comments, we will first describe the situation when we detected TSV from Hawaiian broodstock of Penaeus vannamei. Korean shrimp farmers had previously cultured $P$. monodon and $P$. chinensis but production of these shrimp species rapidly declined due to the spread of white spot syndrome virus (WSSV) (Park et al. 1998, Moon et al. 2003, Seok et al. 2004). As an alternative, since 2002, Korean shrimp farmers have imported $P$. vannamei from various countries. $P$. vannamei is highly susceptible to Taura syndrome virus (TSV) (Brock et al. 1997, Overstreet et al. 1997); however, Korea was considered to be free of TSV and, in order to prevent the introduction of TSV, NFRDI screens every imported stock of shrimp for specific pathogens, especially TSV, by RT-PCR. From 2002 to 2004, Korea imported $P$. vannamei from Hawaii and China. In total, 19 consignments of pre-shipment samples were tested for specific pathogens; 10 consignments of broodstocks from Hawaii and 9 consignments of post-larvae from China. Among them, 6 consignments from China tested positive for infectious hypodermal and haematopoietic necrosis virus (IHHNV) and WSSV and were not approved for importation. The other 13 consignments tested negative for specific pathogens and were approved for importation. We did not detect TSV in any of the 19 samples. However, as we reported previously in DAO (Do et al. 2006), in 2004, mass mortality occurred among $P$. vannamei cultured in a shrimp farm on the western coast of Korea and we isolated TSV from the moribund shrimp (KOR- 
CsPv04TSV). After the detection of TSV, we destroyed all the remaining shrimp cultured at the shrimp farm. In addition, we thoroughly screened other shrimp farms for TSV but detected it nowhere else.

In 2005, there were 5 trials to import Penaeus vannamei; 2 consignments of broodstocks from Hawaii and 3 consignments of post-larvae from China. However, the pre-shipment samples from Hawaii and China were found to be positive for TSV and IHHNV, respectively, and the importation of those $P$. vannamei stocks from Hawaii and China was not approved. The detection of TSV from Hawaiian broodstocks of $P$. vannamei was wholly unexpected to us, and we can fully understand why Lightner et al. (2007) dispute our results in their Comment. Therefore, we will further detail what we did with the pre-shipment samples of Hawaiian P. vannamei. We must first point out the discrepancy between the number of pre-shipment samples we received, and the number mentioned by Lightner et al. (2007) in their Comment. They stated in their Comment that the Hawaiian company sent us a sample of 10 adult $P$. vannamei in 2005. However, on March 18, 2005, we received a total of 18 adult $P$. vannamei from the Korea Freight Company; 2 pre-shipment samples of 9 adult $P$. vannamei imported from a single Hawaiian company. At that time, there was no other pre-shipment sample than Hawaiian samples and, thus, there was no possibility of mislabeling. These samples were well packed with envelopes in 2 separate boxes, showed no visible signs of Taura syndrome and came with an official letter of certification for SPF shrimp issued by the State of Hawaii per each sample. On the day we received the samples, we screened them for specific pathogens including TSV, IHHNV, WSSV, and hepatopancreatic parvovirus (HPV) by RT-PCR. In order to exclude any possibility of laboratory contamination, we naturally used sterilized labware and sterilized solutions, and used PCR mixture without cDNA template from shrimp samples as negative control. We did not detect WSSV, IHHNV, or HPV but did detect TSV from both samples (KOR-ImPv05TSV). Analysis of the nucleotide sequences of the PCR products revealed that the PCR-amplified gene was the TSV VP1 gene (Do et al. 2006). We communicated the results to an employee of the Korea Freight Company and asked him to send us additional samples for re-testing. However, there was no response from him and, thus, we could not test other samples. Lightner et al. (2007) state that the shrimp-supply company in Hawaii was informed of the test result and subsequently requested (through the Korea Freight Company) that we carry out additional tests with new samples from the same stock, but that we did not respond to that request. However, we never received any such request from the Korea Freight Company, or from the supplying company in Hawaii. If we had received such a request, we would have done it without hesitation. In fact, in 2006, there were 7 requests for testing with pre-shipment samples of Hawaiian broodstocks of $P$. vannamei. All samples were negative for specific pathogens and the importations were approved. However, the Hawaiian shrimp-supply companies in 2006 were different from that in 2005.

Previously, we reported that the genotype of KORCsPv04TSV and KOR-ImPv05TSV is more closely related to the TSV isolate from Thailand than to those from Americas or elsewhere in Asia (Do et al. 2006). Based on our report, Lightner et al. (2007) concluded that Korean TSV isolates did not come from Hawaii but came from a source in SE Asia. In case of KORCsPv04TSV isolated from cultured shrimp in 2004, it is very difficult to determine the source. During 2002 to 2004, Penaeus vannamei was imported only from Hawaii and China but never from SE Asia, and all preshipment samples of $P$. vannamei imported from Hawaii and China tested negative for TSV. In addition, the Korean peninsula is geographically much closer to Taiwan than to Thailand and thus it is unlikely that the Thailand TSV strain rather than the Taiwan TSV strain would naturally infect shrimp cultured in Korea. Recently, it has been reported that the genotype of Chinese TSV isolates is closely related to TSV isolates from SE Asia (Nielsen et al. 2005, Tang \& Lightner 2005). This suggests that TSV may be introduced into Korea through illegal importation of $P$. vannamei from China; however, we currently have no evidence to support this possibility. In case of KOR-ImPv05TSV, even though we detected it from pre-shipment broodstocks of $P$. vannamei imported from Hawaii, we are unable to explain how the Hawaiian shrimp was contaminated with TSV closely related to Thailand TSV isolates. TSV has not been detected from Hawaiian shrimp since 1994 (Lightner et al. 1995) and the genotype of Hawaiian TSV isolates is different from those of Thailand TSV isolates (Tang \& Lightner 2005). It is unlikely that the Hawaiian pre-shipment samples were contaminated with TSV during either transportation or laboratory testing. We are confident that a collaborating study between NFRDI and the Hawaii Aquaculture Development Program will reveal the source of the TSV isolated from Hawaiian preshipment samples.

Lightner et al. (2007) indicated that there was a mistake in Fig. 2 of our report (Do et al. 2006), in that the TSV with the GenBank Access. No. AF277675 was referred to as a French isolate. Even though the nucleotide sequence of the TSV in AF277675 was identical to that of HI94TSV (GenBank Access. No. AF510518), we did not recognize that the two are from the same isolate. As Lightner et al. (2007) indicated in their comment, the TSV represented by AF277675 is not a French but a 
Hawaiian isolate identical to HI94TSV (AF510518). We have removed the TSV represented by AF277675 from Fig. 2 of our report (Do et al. 2006) and the corrected figure is shown in our Erratum (this issue, p. 84). However, we think that this change does not affect the validity of our data or our conclusions.

In summary, we confirm that there was no mislabeling of samples and no laboratory contamination during the testing of Hawaiian pre-shipment samples. In addition, we attempted to provide the Hawaiian shrimpsupply company with an opportunity for re-testing with additional samples but were unsuccessful. We believe that this was not because we ignored the request from the Hawaiian supplying company, but rather because requests from both sides were not properly delivered to the other. We recognize and applaud the effort made in Hawaii to develop and keep SPF shrimp. Despite the detection of TSV from Hawaiian pre-shipment shrimp in 2005, we continue to believe that the Hawaiian shrimp culture industry produces the best shrimp and, thus, in 2006, Korea imported broodstocks of Penaeus vannamei from Hawaii.

\section{LITERATURE CITED}

Brock JA, Gose RB, Lightner DV, Hasson KW (1997) Recent developments and an overview of Taura syndrome of farmed shrimp in the Americas. In: Flegel TW, MacRae IH (eds) Diseases in Asian aquaculture III. Asian Fisheries Society, Manila, p 275-283

Do JW, Cha SJ, Lee NS, Kim YC, Kim JW, Kim JD, Park JW (2006) Taura syndrome virus from Penaeus vannamei shrimp cultured in Korea. Dis Aquat Org 70:171-174

Lightner DV, Redman RM, Hasson KW, Pantoja CR (1995)

Editorial responsibility: Managing Editor
Taura syndrome in Penaeus vannamei (Crustacea: Decapoda): gross signs, histopathology and ultrastructure. Dis Aquat Org 21:53-59

Lightner DV, Riggs A, Corbin, JS, Ostrowski AC (2007) Taura syndrome virus in specific pathogen-free Penaeus vannamei originating from Hawaii and in $P$. vannamei stocks farmed in France? Dis Aquat Org 74:77-79

Moon CH, Do JW, Cha SJ, Yoon WJ and 7 others (2003) Highly conserved sequences of three major virion proteins of a Korean isolate of white spot syndrome virus (WSSV). Dis Aquat Org 53:11-13

Nielsen L, Sang-oum W, Cheevadhanarak S, Flegel TW (2005) Taura syndrome virus (TSV) in Thailand and its relationship to TSV in China and the Americas. Dis Aquat Org 63:101-106

Overstreet RM, Lightner DV, Hasson KW, McvIlwain S, Lotz JM (1997) Susceptibility to Taura syndrome virus of some penaeid shrimp species native to the Gulf of Mexico and the Southeastern United States. J Invertebr Pathol 69: 165-176

Park JH, Lee YS, Lee S, Lee Y (1998) An infectious viral disease of penaeid shrimp newly found in Korea. Dis Aquat Org 34:71-75

Pruder GD, Brown CL, Sweeney JN, Carr WH (1995) High health shrimp systems: seed supply - theory and practice. In: Browdy CL, Hopkins JS (eds) Swimming through troubled water. Proceedings of the special session on shrimp farming, Aquaculture '95. World Aquaculture Society, Baton Rouge, LA, p 40-52

Seok SH, Park JH, Cho SA, Baek MW, Lee HY, Kim DJ, Park $\mathrm{JH}$ (2004) Cloning and sequencing of envelope proteins (VP19, VP28) and nucleocapsid proteins (VP15, VP35) of a white spot syndrome virus isolate from Korean shrimp. Dis Aquat Org 60:85-88

Tang KF, Lightner DV (2005) Phylogenetic analysis of Taura syndrome virus isolates collected between 1993 and 2004 and virulence comparison between two isolates representing different genetic variants. Virus Res 112:69-76

Wyban JA, Swingle JS, Sweeney JN, Pruder GD (1993) Specific pathogen free Penaeus vannamei. World Aquacult $24: 39-45$

Submitted: November 18, 2006; Accepted: December 11, 2006 Proofs received from author(s): December 22, 2006 